\title{
Research of R\&D Marginal Productivity Driving Economic Convergence
}

\author{
Ren Lingyu \\ Institute of Policy and Management \\ Chinese Academy of Sciences \\ City, Country \\ rly1618@126.com
}

\author{
Wang Zheng \\ Institute of Policy and Management \\ Chinese Academy of Sciences \\ City, Country \\ wangzheng@casipm.ac.cn
}

\begin{abstract}
The convergence mechanisms of regional economics have become one of hot issues. In this paper we propose the concept of $R \& D$ marginal productivity to study economic convergence, which is defined as the economic marginal product relative to $R \& D$ capital stock. We find: whether from the angle of $\sigma$ convergence or from dynamic evolution of kernel density distribution, $R \& D$ marginal productivity diverges from the year 1999 to 2001, while converges from 2001 to 2009; GDP per labor diverges from 2000 to 2002, and converges from 2002 to 2010 . The convergence of GDP per labor lags one period relative to $R \& D$ marginal productivity. That confirms that $R \& D$ marginal productivity drives the convergence of GDP per labor. We also find there are some other convergence mechanisms to play roles in China.
\end{abstract}

Keywords-convergence mechanism; $R \& D$ marginal productivity; $\sigma$ convergence; kernel density distribution

\section{INTRODUCTION}

Marked by the Great Development of Western in 1999, China started the strategy of coordinated development of regional Economy to decrease the economic gap between the eastern and western parts. How are the effects of the strategy? What mechanisms can reduce economic gap? All these have already attracted the attentions of scholars. Reducing the economic gap is the problem of Economic Convergence in academic fields.

Grossman and Helpman (1991) proposed technology and innovation diffusion theory ${ }^{[1]}$. They thought that imitation was cheaper than innovation, backward countries would learn and imitate the technologies of the leaders, and finally the technologies among all countries would tend toward the same level to result in economic convergence. Jones (1995, 1999) and Young (1998) admitted that equivalent R\&D inputs didn't lead to equivalent innovative outputs when technological level advanced to some extent, the revenue of technological innovation would decrease ${ }^{[2-4]}$. Yang and Borland (1991), Aghion and Howitt(1998) considered that the transaction cost in innovative activities would heavily increase as the enhancement of specialization level and complex of technology ${ }^{[5,6]}$. From their researches, we will draw some conclusions that the cost of technological innovation presents the characteristic: "decreasing first, increasing later". So, the technological levels between developing and developed countries will converge and the economic levels also converge.

It has already had many papers about whether the economic convergence exists among Chinese regions. But about the convergence mechanism, it appears deficient. Zhao and Ma (2005) studied the three kinds of mechanisms: capital convergence mechanism, technology convergence mechanism and labor productivity convergence mechanism ${ }^{[7]}$. Xia (2009) proposed a modified Dowrick-Rogers model to analyze neoclassical and new-growth convergence mechanisms ${ }^{[8]}$. Wu (2010) compared four kinds of convergence mechanisms: TFP (total factor productivity), effective material capital per labor, human capital and institutional efficiency ${ }^{[9]}$.

The technological convergence mechanism in these papers could be divided into two categories. The first is based on the TFP. They directly thought TFP as the technology level. The second is directly based on the technology diffusion model. The two kinds of convergence mechanism both have shortages. First, TFP includes not only technology efficiency but also many other efficiency factors, for instance, institutional efficiency, organizational innovation, specialization, and so on. Second, the technology diffusion model only considers the technological absorption from the developed countries, no considering independent innovation.

Romer(1990 $)^{[10]}$, Aghion and Howitt(1992) ${ }^{[11]}$, Jones(1995) ${ }^{[2]}$, Acemoglu(1998) ${ }^{[12]}$ all considered purposeful R\&D(Research and Development) as sources of technological progress. So we propose the concept of R\&D marginal productivity to study economic convergence. R\&D marginal productivity is defined as the economic marginal product relative to $R \& D$ capital stock, and $R \& D$ capital stock could describe the technological absorption capacity and self-innovation capacity. R\&D marginal productivity could directly connect technology progress to economic convergence. R\&D capital stocks exclude these TFP factors of institutional efficiency, organizational innovation, specialization. So using R\&D marginal productivity to study economic convergence is more accurate than TFP and more scientific than the technology diffusion model.

The structure of the paper is as follows. Section 2 introduces the measurement model of R\&D marginal productivity, and explains the related data. Section 3 presents the results of measurement, and analyzes convergence of the R\&D marginal productivity. Finally, summarizes the conclusions. 


\section{MODEL AND DATA}

\section{A. Model}

We first consider C-D production function ${ }^{1}$ :

$$
Y_{i t}=A_{i t} L_{i t}^{\alpha} K_{i t}^{\beta} \text {. }
$$

Where $Y, A, L$ and $K$ respectively denote gross output, TFP, labor and capital stock. $\alpha$ and $\beta$ denote output elasticity of labor and capital, and $\alpha+\beta=1, i$ and $t$ stand for provinces and years. Assuming $\mathrm{R} \& \mathrm{D}$ capital stock equals $X$, we construct the following TFP equation.

$$
A_{i t}=B_{0} e^{\sigma T} X_{i t}^{\rho} \text {. }
$$

Where $B_{0} e^{\sigma T}$ describes the exogenous technology progress (the growth rate per year is $\sigma$ ), and $\rho$ denotes the economic output elasticity of R\&D capital stock, i.e. $\rho=\frac{\partial Y}{\partial X} \cdot \frac{X}{Y}$.

For Eq. (2), we take difference with respect to time, then:

$$
\frac{\Delta A_{i t}}{A_{i t}}=\sigma+\rho \frac{\Delta X_{i t}}{X_{i t}} \text {. }
$$

Assuming $R \& D$ capital stock at time $t$ can be represented as the current value of $R \& D$ expenditure of all the past times and the current value of R\&D capital stock at time $t-1$ (Griliches, 1980) ${ }^{[13]}$. Using $R_{t}$ denotes R\&D actual expenditure, then:

$$
X_{t}=\sum_{k=1}^{t} \mu_{k} R_{t-k}+(1-\delta) X_{t-1} .
$$

Where $k$ is lag period, $\mu_{k}$ denotes discount coefficient of $\mathrm{R} \& \mathrm{D}$ expenditure, $\delta$ is depreciation rate. Let average lag time equals to $\theta$, and $\mu_{\theta}=1$. Then equation (4) could be expressed as:

$$
X_{t}=R_{t-\theta}+(1-\delta) X_{t-1} .
$$

$\mathrm{R} \& \mathrm{D}$ capital depreciation is the process of ageing and outdating of knowledge stock. Griffith et al. (2000) assuming $\delta$ is anti-function of the revenue time length of patents ${ }^{[14]}$. If the lifetime of patent is long enough, $\delta$ will be very small. We assume that $\delta$ and $\theta$ are small enough. We obtain that $X_{t}=R_{t}+X_{t-1}$, i.e. $\Delta X_{t}=R_{t}$. Both sides are divided by $X_{t}$, then:

$$
\Delta X_{t} / X_{t}=R_{t} / X_{t}
$$

Combining equation (6) and $\rho=\frac{\partial Y}{\partial X} \cdot \frac{X}{Y}$ into Eq. (3), then:

\footnotetext{
${ }^{1}$ Griffith et al. (2001) offered the similar derivation process in their paper "Mapping the Two Faces of R\&D: Productivity Growth in a Panel of OECD Industries". They studied the two faces of R\&D.
}

$$
\frac{\Delta A_{i t}}{A_{i t}}=\sigma+\frac{\partial Y_{i t}}{\partial X_{i t}} \cdot \frac{X_{i t}}{Y_{i t}} \cdot \frac{R_{i t}}{X_{i t}} .
$$

$$
\text { Let } \eta=\frac{\partial Y_{i t}}{\partial X_{i t}} \text {. Substituting Eq. (7) into Eq.(1) and adding }
$$

random error $\varepsilon_{\text {it }}$, we obtain the following equation:

$$
\frac{\Delta Y_{i t}}{Y_{i t}}=\sigma+\alpha \frac{\Delta L_{i t}}{L_{i t}}+\beta \frac{\Delta K_{i t}}{K_{i t}}+\eta \frac{R_{i t}}{Y_{i t}}+\varepsilon_{i t} .
$$

Where $\alpha+\beta=1$, and $\eta$ describes every regional $\mathrm{R} \& \mathrm{D}$ marginal productivity. In order to the convenience of estimation, we will estimate Eq. (9).

$$
\left(\frac{\Delta Y_{i t}}{Y_{i t}}-\frac{\Delta K_{i t}}{K_{i t}}\right)=\sigma+\alpha\left(\frac{\Delta L_{i t}}{L_{i t}}-\frac{\Delta K_{i t}}{K_{i t}}\right)+\eta \frac{R_{i t}}{Y_{i t}}+\varepsilon_{i t} .
$$

\section{B. Data and Sample}

All data comes from Yearbook of Science and Technology of China and China Statistical Yearbook from 1998 to 2011. We only choose 30 provinces in China, excluding these regions of Tibet, Taiwan, Hong Kong and Macao because of the missing of data.

We choose the year 1998 as the base period. Because of lacking of $R \& D$ price index, we compute $R \& D$ expenditure price index $P I=0.45 P I_{i}+0.55 P I_{c}$ according to the study of Zhu and $\mathrm{Xu}(2003)^{[15]}$, where $P I_{i}, P I_{c}$ respectively denote price index in fixed assets and consumer price index. Because statistical yearbook doesn't exhibit material capital stock, we use perpetual inventory method (Eq. (10) and (11)) to compute the capital stock of each province.

$$
\begin{gathered}
K_{i, t}=(1-\delta) K_{i, t-1}+E_{i, t-1} . \\
K_{i, 0}=E_{i, 0} /(g+\delta) .
\end{gathered}
$$

Where $E_{i, t-1}, E_{i, 0}$ respectively denote fixed assets investment at times $t-1$ and $0, g$ denotes the average growth rate of fixed assets investment, $\delta$ is capital depreciation rate. According to Zhang's conclusion (2004), we let $\delta=9.6 \%{ }^{[16]}$.

\section{RESULTS AND ANALYSIS}

\section{A. R\&D Marginal Productivity}

In order to obtain the values of $R \& D$ marginal productivity in different provinces and during 1999-2010, we consider Eq. (9) as the hierarchical liner modeling ${ }^{2}$. We consider the R\&D marginal productivity varying as background variables of the time and region, and labor elasticity varying as background variable of time. The estimation results see Tables I and II.

In Table I, the P-values of every regression coefficient show statistically significant at the 5\% level. In Table II, all the standard deviation estimations of random parameters are

${ }^{2}$ Professor Goldstein from London University calls the model as multilevel liner modeling; Professor Raudenbush from University of Michigan calls the model as Hierarchical liner modeling. 
TABLE I. ESTIMATION OF EQUATION (9)

\begin{tabular}{ccc}
\hline & coefficient & P-Value \\
\hline$\alpha$ & 0.365 & 0.000 \\
$\eta$ & 0.809 & 0.022 \\
constant & -0.076 & 0.000 \\
\hline \multicolumn{2}{c}{ Note: ***denote significant at the 1\% level; } \\
** Significant at the 5\% level.
\end{tabular}

TABLEII. RADOM EFFECT PARAMETERS OF EQUATION (9)

\begin{tabular}{|c|c|c|}
\hline Radom parameters & Estimate & Std. Err. \\
\hline \multirow[t]{2}{*}{ Year: } & 0.211 & 0.049 \\
\hline & 1.130 & 0.286 \\
\hline Province: $\operatorname{sd}(\eta)$ & 0.852 & 0.213 \\
\hline sd(constant) & 0.042 & 0.007 \\
\hline
\end{tabular}

above three times larger than the standard errors, and they explain that the random effects are at least significant at the 1\% level. $\chi^{2}(5)=190.00$ in the model and $\mathrm{P}=0.000$, they explain hierarchical liner model are better than fixed coefficient model. That is to say, R\&D marginal productivities are different in different years and provinces. We give the average values of $R \& D$ marginal productivity during 1999-2010, as is exhibited in Table III.

TABLEIII. R\&D MARGINAL PRODUCTIVITIES PER YEAR DURING 1999-2010

\begin{tabular}{ccccccc}
\hline Year & 1999 & 2000 & 2001 & 2002 & 2003 & 2004 \\
R\&D marginal productivity & 0.95 & 1.00 & 3.97 & -0.17 & 0.36 & 0.82 \\
\hline Year & 2005 & 2006 & 2007 & 2008 & 2009 & 2010 \\
R\&D marginal productivity & 0.73 & 0.28 & 0.27 & 0.40 & 0.30 & 0.78 \\
\hline
\end{tabular}

The values of $R \& D$ marginal productivity vary as years and provinces. Because $R \& D$ marginal revenue is characteristic of increase first and decrease later, $R \& D$ marginal productivity also own the feature. Even some values of $R \& D$ marginal productivity show negative. However, it is normal. Increasing R\&D input means decreasing the material capital of production activities. And because $\mathrm{R} \& \mathrm{D}$ marginal revenue decreases progressively, the technological progress caused by increasing $R \& D$ input could not offset the decrease of economic output caused by decreasing production input. So the R\&D marginal productivity could be negative. Sure, there are many other factors influencing the R\&D marginal productivity, we will specialize in them in another paper.

\section{$B$. The $\sigma$ - convergences of $R \& D$ marginal productivity and GDP per labor}

The $\sigma$ convergence is commonly used to check the economic convergence. If the $\sigma$ values decrease as time elapses, it means economic convergence. In the paper, we use Eq. (12) to calculate the $\sigma$ values of GDP per labor, and Eq. (13) to calculate the $\sigma$ values of $R \& D$ marginal productivity.

$$
\sigma^{2}=\frac{1}{n} \sum_{i=1}^{n}\left(\ln y_{i, t}-\frac{1}{n} \sum_{i=1}^{n} \ln y_{i, t}\right)^{2} .
$$

$$
\sigma^{2}=\frac{1}{n} \sum_{i=1}^{n}\left(y_{i, t}-\frac{1}{n} \sum_{i=1}^{n} y_{i, t}\right)^{2} .
$$

In order to comparison, we standardize the two $\sigma$ values. The convergence trends of two variables are shown in Fig. 1.

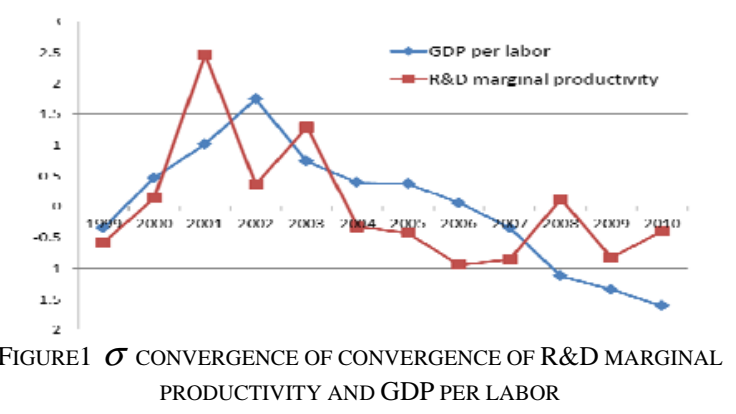

In Fig. 1, R\&D marginal productivity show convergent after the year 2001, and divergent before 2001; GDP per labor converges after 2002 and diverges before 2002. The convergence of GDP per labor lags one period relative to R\&D marginal productivity. The Pearson correlation coefficient of the two $\sigma$ curves equals to $0.5384(\mathrm{P}=0.071)$. If we consider the one-period lag, the Pearson correlation coefficient will be $0.6659(\mathrm{P}=0.025)$. Obviously, the lag period increases the statistical significance of the correlation. It just proves that the convergence of $R \& D$ marginal productivity drives the convergence of GDP per labor and that there is one period lag.

\section{Dynamic evolution of the convergences of $R \& D$ marginal productivity and GDP per labor}

Dynamic distribution method mainly comprises kernel density distribution method and Markov probability distribution method ${ }^{3}$. Kernel density distribution method is a kind of non-parameter method. It directly draws convergent conclusions from data, so it could be the most accurate way to study convergence problem. Moreover kernel density curve is very visual and intuitional. We will choose kernel density distribution to study the convergences of $R \& D$ marginal productivity and GDP per labor.

According to $\sigma$ convergence, there is one-period lag between the convergences of R\&D marginal productivity and GDP per labor. So we choose the years 1999, 2001 and 2009 to draw the kernel density distribution curves of R\&D marginal productivity, and choose the years 2000, 2001 and 2010 to draw the curves of GDP per labor. These curves could be seen in Fig. 2.

If the peak of kernel density curve becomes higher and the bottom becomes narrower, it means that the economic variable converges. In Fig. 2, R\&D marginal productivity diverges from 1999 to 2001, and converges from 2001 to 2009; GDP per labor diverges from 2000 to 2002, and converges from 2002 to 2010. On the condition of oneperiod lag, the two phases and steps of divergences and convergences can almost match. So the kernel density curves

\footnotetext{
${ }^{3}$ For further details, see Quah(1993) and Jones(1997).
} 
prove the existences of convergence of $R \& D$ marginal productivity and GDP per labor, and R\&D marginal productivity driving the convergence of GDP per labor.
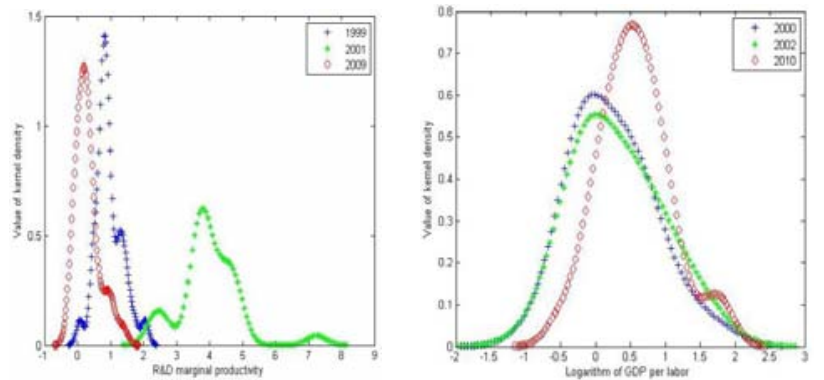

FIGURE 2. KERNEL DENSITY CURVES OF R\&D MARGINAL PRODUCTIVITY AND GDP PER LABOR

Note: As mentioned earlier in the paper, R\&D marginal productivity increases first and decreases later as R\&D input continuously increases. Because the unit of GDP per labor is one hundred million yuan per ten thousand people, its logarithm value could be negative.

However, we should find that the $\sigma$ convergences and the convergences of kernel density distribution between R\&D marginal productivity and GDP per labor don't match perfectly. Obviously, the added height of peak of R\&D marginal productivity from 2001 to 2009 is less than that of GDP per labor from 2002 to 2010 in Fig. 2. It implies that there are some other mechanisms to drive GDP per labor to converge. For instance, Wu (2010) proposed that material capital per labor offers $21.6 \%$ contribution to the convergence of GDP per labor using the method of variance decomposition ${ }^{[9]}$. In another word, besides R\&D marginal productivity can drive the convergence of GDP per labor, there are some other convergent mechanisms to play roles.

\section{CONCLUSIONS}

This paper has proposed the concept of R\&D marginal productivity to study if technology progress drives the economic convergence in China. R\&D marginal productivity is defined as the economic marginal product relative to $R \& D$ capital stock. We have drawn some conclusions.

First, for $\sigma$ convergence, R\&D marginal productivity diverges from the year 1999 to 2001, while converges from 2001 to 2009; GDP per labor diverges from 2000 to 2002, and converges from 2002 to 2010. The Pearson correlation coefficient of the $\sigma$ curves equals to $0.5384(\mathrm{P}=0.071)$ (no considering one-period lag). The Pearson correlation coefficient of the two convergence variables will be 0.6659 $(\mathrm{P}=0.025)$ and significant at the $5 \%$ level (considering oneperiod lag). It explains that the convergence of GDP per labor is significantly related to R\&D marginal productivity. Further, one-period lag rightly explains that R\&D marginal productivity drives the convergence of GDP per labor.

Second, the kernel density distribution curve of $R \& D$ marginal productivity demonstrates that it diverges from the year 1999 to 2001 and converges from 2001 to 2009. By contrast, the kernel density curve of GDP per labor demonstrates that it diverges from the year 2001 to 2002 and converges from 2002 to 2010. The dynamic evolution results of kernel density distributions further prove the conclusions of $\sigma$ convergence.

Finally, whether from the angle of $\sigma$ convergence or from dynamic evolution of kernel density distribution, the main steps and rhythm of the convergences are similar, but they are not completely the same. As proved by other scholars, there are some other convergence mechanisms to drive economic convergence in China also.

\section{ACKNOWLEDGMENT}

This paper gets much help from national natural key science fund of China (Research of management model for the regional coordination based on the mechanism of territorial spatial differentiation, NO. 70933002). We express our heartfelt thanks here.

\section{REFERENCES}

[1] Grossman,G.M.and Helpman,E., Innovation and Growth in the Global Economy[M].The MIT Press,1991.

[2] Jones,C.I., R\&D-Based Models of Economic Growth[J].Journal of Political Economy,1995,103:759-784.

[3] Jones,C.I., Growth: With or Without Scale Effects[J].American Economic Review,1999,89:139-144.

[4] Young,A., Growth without Scale Effects[J].Journal of Political Economy,1998,106:41-63.

[5] Yang,Xiaokai and Borland,J., A Microeconomic Mechanism for Economic Growth[J].Journal of Political Economy,1991,99:460-482.

[6] Aghion,P. and Howit,P., Endogenous Growth Theory[M].Cambridge:The MIT Press,1998.

[7] Zhao Wei,Ma Ruiyong. Recognition on the Convergence of Economic Growth in China: Based on the convergent micromechanism [J].Management World, 2005, 11:12-21.

[8] Xia Wan-jun. A Study on Mechanisms of Regional Economic Convergence in China [J].Journal of business economics, 2009, 9:5257.

[9] Wu Lixue.Study on the Regional Convergence during the Economic Transition of China [M].Economic \& Management Publishing House, 2010.

[10] Romer,P.M., Endogenous Technological Change[J].Journal of Political Economy,1990,98:71-102.

[11] Aghion,P. and Howit,P., A Model of Growth through Creative Destruction[J].Econometrica,1992,60:323-351.

[12] Acemoglu,D., Why Do New Technologies Complement Skills? Directed Technical Change and Wage Inequality [J].Quarterly Journal of Economics, 1998, 113:1055-1089.

[13] Griliches,Z., R\&D and Productivity Slowdown[J].American Economic Review,1980, 70:343-348.

[14] Griffith,R., Redding,S. and Van Reenen,J., Mapping the Two Faces of R\&D: Productivity Growth in a Panel of OECD Industries, CEPR Discussion Paper, 2000.

[15] Zhu Pingfang,Xu Weimin. On The Impact of Government's S\&T Incentive Policy on the R\&D input and its patent output of large and medium-sized Industrial enterprises in Shanghai[J].Economic Research Journal,2003,6:45-53.

[16] Zhang Jun,Wu Guiying,Zhang Jipen. The Estimation of China's provincial capital stock: 1952-2000[J]. Economic Research Journal, 10:35-44. 